\title{
'Margin Insensitivity' and the Analysis of Educational Inequality*
}

\author{
OTTAR HELLEVIK** \\ University of Oslo
}

\begin{abstract}
A problem in educational attainment research is that measures of association, and not measures of inequality, have been used to observe inequality in the distribution of higher education between classes. While the statistical association between class and education in many countries has been relatively stable, measures of inequality applied to the same data show a marked reduction of inequality in the distribution of higher education over time. This is a result of reduced bias in the allocation mechanisms, most likely facilitated by the increasing provision of higher education. Decreasing inequality means that the conclusion in the literature that egalitarian educational reforms have been ineffective lacks empirical support. One reason why measures of inequality have been overlooked in most educational attainment research may be the firm but unfounded belief in the 'margin insensitivity' of loglinear measures. They are assumed to capture the association net of changes in the marginals of the class-by-education table, thus reflecting the 'true nature' of the allocation mechanism in recruitment to higher education. This notion can be shown to be a logically untenable deduction from the property of loglinear measures of being insensitive in relation to one specific kind of change in the marginals, to the claim that these measures are insensitive to marginal changes in general.
\end{abstract}

Keywords: social inequality, inequality of educational attainment, loglinear measures, measures of inequality, margin insensitivity

Sociologický časopis/Czech Sociological Review, 2007, Vol. 43, No. 6: 1095-1119

\footnotetext{
* This is a revised version of a paper presented at the Spring Meeting of the Research Committee on Social Stratification and Mobility (RC28) in Brno, Czech Republic, 24-27 May 2007. I wish to thank participants at the conference, in particular John Logan, Samuel Lucas, Yossi Shavit and Louis-Andre Vallet, for valuable criticism and suggestions, some of which has been incorporated into the text. I also have benefited from comments from Knut Andreas Christophersen, Tale Hellevik, Jon Hovi, and Axel West Pedersen, and from assistance from Nils Olav Refsdal. The core argument of the article emerged from my collaboration and discussions with Stein Ringen, begun during my stay at Oxford University in 1992.

** Direct all correspondence to: Ottar Hellevik, Department of Political Science, University of Oslo, PO Box 1097, Blindern, N-0317, Norway, e-mail: ottar.hellevik@stv.uio.no.
} 


\section{Introduction}

All societies exhibit systematic inequalities in the access they provide social groups to privileged positions and attractive goods. This finding, discussed under the terms social stratification and class inequality, is one that may qualify as a law in social science. Moreover, it has been shown that these inequalities are passed on from generation to generation through biases in the processes of allocation that favour the offspring of privileged parents, in what is called the social reproduction of inequality.

The education system plays a key role in the allocation of attractive positions and goods in modern society. Higher education can be regarded as a good in its own right, and possessing it opens up access to rewarding occupational positions. At the beginning of the 20th century, higher education was mainly available to the children of well-off parents. But with the expansion of higher education in the second half of the century an increasing number of children from less privileged social groups were given access to institutions of higher learning. However, according to prominent researchers in this field, this did not reduce the class inequality in educational attainment. The dominant view is that the extensive egalitarian reforms of the school system in this period failed to achieve their goals. However, this view has been challenged. According to critics, there has in fact been a remarkable reduction of class inequality in access to higher education. These conflicting conclusions, drawn from empirical analyses of the same data, depend on the choice of statistical measures for comparing class-by-education tables at different points in time. Linear and loglinear measures of association show stable social differences in access to higher education. In contrast, measures of inequality show that social differences are decreasing.

My interest in the question of how to measure inequality in educational attainment stems from my discussions with Professor Stein Ringen on my visit to Oxford University in the autumn of 1992. What struck me when he told me of his misgivings about the conclusions drawn in the class inequality literature was that a debate within my own field of political science was highly relevant to the problem. In 1981 William Lafferty wrote a book [1981] criticising the conclusions reached by Willy Martinussen in The Distant Democracy: Social Inequality, Political Resources and Political Influence in Norway [1977]. Martinussen had concluded that political participation in Norway was heavily skewed, and that the lack of participation by less privileged groups contributed to preserving social inequality. Lafferty claimed that the differences between the groups were far too small to talk about socially biased participation.

My contribution to the debate was to point out that a criterion for judging whether a difference in participation should be regarded as large or small is how it affects the social composition of the participants [Hellevik 1983]. If we look at an activity in which only a minority participate, for example, being a member of a political party, the existence of a gap of ten percentage points, say between $10 \%$ 
participating in one class and $20 \%$ in another, results in a highly skewed distribution of members across classes. The same gap of ten percentage points would have a much less adverse effect on the representativity of voters if the participation levels in the two classes were, say, $80 \%$ versus $90 \%$. The distribution across classes for voters would be $53-47 \%$ compared to $33-67 \%$ for party members (when the classes are of equal size). In other words, the higher the participation level, the less an absolute difference or gap in participation between the groups affects the social representativity of the participants.

This view has not met with any opposition in the debate among political scientists. But in research on educational attainment, many scholars evidently believe that loglinear measures somehow control for differences in the level of participation. These measures are believed to be 'margin insensitive', capturing the association net of changes in class composition and educational provision. This belief has been a major obstacle to reaching an agreement in the debate on how the class-education relationship has developed. The purpose of this paper is to show that the idea of margin insensitivity is unfounded.

Below I will give an example of how the same empirical data can be interpreted differently depending on which statistical measure is chosen to describe them. I will then proceed to take a more general look at the properties of three main classes of measures: linear and loglinear measures of association, and measures of inequality. I challenge from several perspectives the notion that loglinear measures are suited to capturing bias in the allocation mechanism, and that such bias is something other than inequality of the distribution of higher education across classes captured by inequality measures. First, I argue that the basic premise, the assumed margin insensitivity of loglinear measures, is untenable, and then I explain why loglinear measures are not suited to capturing bias in allocation mechanisms. Loglinear measures are not as different from linear measures of association as is commonly assumed, and they give nonsensical results for allocation bias once the level of educational provision is high. By using sampling procedures as models for recruitment to higher education, I will demonstrate that it is measures of inequality, rather than loglinear measures, that capture the bias of the allocation mechanism.

\section{Persistent inequality?}

In Table 1 British data is used to illustrate the dramatic divergence of results for different classes of statistical measures. The statistical measures (except the Gini coefficient) are calculated from the proportion of people in three social classes that are enrolled in higher education, and the development over time is captured by making these calculations for four consecutive birth cohorts. The 'raw' proportions for each class are shown in the upper rows of the table, followed by rows for each statistical measure. The first of these - the proportion difference (PD) 
between the upper and lower classes - is a linear measure of association, and shows stable values at around 0.4 for the first three cohorts, and a little less for the fourth cohort. The same impression of stability also holds for loglinear measures of association, the statistic preferred by researchers in this field.

From these and similar findings of a stable association over time, most people studying higher education recruitment have concluded that class inequality has remained unchanged. And because social inequality persists despite educational reforms aimed at reducing inequality, the empirical results have been taken as proof that these egalitarian reforms have been ineffective. In the introduction to a publication presenting studies from thirteen different countries, Blossfeld and Shavit state:

In sum, despite the marked expansion of all the educational systems under study, in most countries there has been little change in socioeconomic inequality of educational opportunity. [Blossfeld and Shavit 1993: 19]

Finally, the impact of educational reforms on changes in educational stratification seems to be negligible. Nowhere have they reduced inequalities of educational opportunity between socioeconomic strata. [Ibid.: 21]

But as pointed out elsewhere [Hellevik 1997, 2000, 2002; Ringen 1997, 2000, 2005, 2006], and as shown in Table 1, a very different picture emerges when the same data are analysed with a measure designed to capture inequality in the distribution of a good. The participation ratio is a simple measure of inequality, found as the ratio of the proportion of people with higher education in one group to that in another group. The table shows the ratio for the lower versus the upper class, which varies between 0 and $1 .^{1}$ This may be taken as a measure of equality, with the maximum value of 1 implying complete equality. Because high inequality corresponds to strong association, an 'inequality coefficient' (IC) is defined as $1-\mathrm{PR}$. According to this measure, from the first to the last cohort the inequality has been nearly halved.

A more complex measure of inequality is the bivariate version of the Gini coefficient - the so-called coefficient of concentration - which measures the degree to which a good (in this case higher education) is concentrated across a population grouped according to a different variable (in this case social class). ${ }^{2}$ The coefficient is calculated by comparing the cumulative distribution of places in higher

\footnotetext{
${ }_{1}^{1}$ This is of course provided that the proportion for the lower class is below or equal to that of the upper class.

2 The groups are ranked according to their advantage ratio (the proportion of the good divided by the proportion of the population). See Lambert [1993] for a formal exposition of the Gini-coefficient of concentration. The calculation of the coefficient for this table is shown in Hellevik [1997] and Ringen [1997].
} 
Table 1. Class and educational attainment: measures of association and inequality

\begin{tabular}{lcccc}
\hline & \multicolumn{4}{c}{ Birth cohort } \\
& $1930-39$ & $1940-49$ & $1950-59$ & $1960-69$ \\
\hline Proportion of the pop. with higher education & & & & \\
$\quad$ Upper class, $\mathrm{P}_{\mathrm{U}}$ & 0.58 & 0.67 & 0.84 & 0.87 \\
$\quad$ Middle class, $\mathrm{P}_{\mathrm{M}}$ & 0.31 & 0.46 & 0.58 & 0.74 \\
$\quad$ Lower class, $\mathrm{P}_{\mathrm{L}}$ & 0.18 & 0.27 & 0.42 & 0.54 \\
\hline Linear association & & & & \\
$\quad$ Proportion difference & 0.40 & 0.40 & 0.42 & 0.33 \\
$\quad$ PD $=\mathrm{P}_{\mathrm{U}}-\mathrm{P}_{\mathrm{L}}(=$ linear $\mathrm{b})$ & 100 & 100 & 105 & 83 \\
$\quad$ 1930-39 $=100$ & & & & \\
\hline Loglinear association & 0.46 & 0.43 & 0.49 & 0.42 \\
$\quad$ Lambda $=1 / 4 \mathrm{ln}$ OR \\
1930-39 $=100$ & 100 & 93 & 107 & 91 \\
\hline Inequality & & & & \\
$\quad$ Participation ratio $\mathrm{PR}=\mathrm{P}_{\mathrm{L}} / \mathrm{P} \mathrm{P}_{\mathrm{U}}$ & 0.31 & 0.40 & 0.50 & 0.62 \\
$\quad$ Inequality coefficient $\mathrm{IC}=1-\mathrm{PR}$ & 0.69 & 0.60 & 0.50 & 0.38 \\
1930-39 $=100$ & 100 & 87 & 72 & 55 \\
\hline Gini-coefficient & 0.24 & 0.20 & 0.15 & 0.10 \\
1930-39 $=100$ & 100 & 80 & 60 & 44 \\
\hline
\end{tabular}

Source: Hellevik [1997], based on British data used in Heath and Clifford [1990].

education across the three classes in the table with the classes' cumulative share of the population. The more the distribution of higher education is concentrated among the upper class, the closer to 1 the result for the Gini-coefficient will be. ${ }^{3}$ If every group gets a share of positions in higher education in direct proportion to its share of the population, the Gini-coefficient is 0 . The reduction shown in Table 1, as we move from older to younger cohorts, indicates that the distribution of places of higher education across classes over time becomes closer and closer to the distribution of the population. Or to put it another way, the social composi-

\footnotetext{
${ }^{3}$ A problem not considered here is that the grouping of cases implies that the Gini-coefficient of concentration has a restricted range; it cannot reach 1 [Leege and Francis 1974]. The range of the coefficient becomes increasingly restricted as the upper class's share of the population increases. However, this is of no relevance to the discussion of trends in Table 1.
} 
tion of those members of the population attaining a higher education becomes steadily more representative for the entire population. ${ }^{4}$

An alternative interpretation of what has taken place in the education system in the past century is that the importance of class for the probability of attaining a higher education remains strong throughout the period. In a path-analytic framework, this would be interpreted as a strong and stable causal effect of class on education. But the decrease in inequality measures tells us that a rising level of education in the population and a stable association between class and education jointly have produced a steady reduction in the degree of inequality in the distribution of higher education across classes.

\section{Three types of measures for the class-education relationship}

At this point it may be useful to take a more general look at the properties of the three kinds of statistical measures used to describe the contents of the class-byeducation table: linear measures of association, loglinear measures of association, and measures of inequality. Figure 1 compares how the three measures behave in a hypothetical scenario, in which the provision of higher education increases which is the historical trend - while the linear association between class and education remains stable. In Figure 1, the PD (the absolute difference in proportions) is kept constant at 0.20 . The PD is identical to the linear regression coefficient in the bivariate case. It varies between a minimum of 0 , when the proportions are identical, and plus/minus 1 for maximum association, when the proportion is 0 in one of the groups and 1 in the other. The interpretation is straightforward as it shows the absolute difference or gap between two classes in the probability of obtaining higher education.

The loglinear measures, here represented by the Lambda coefficient, cannot be given such a simple and intuitively meaningful explanation. The Lambda is defined as one-quarter of the logistic regression coefficient, which in turn is the natural logarithm of the odds ratio; this is the ratio between two odds, each being a ratio between the proportion having and the proportion not having obtained a higher education. The reason for using the Lambda in the figure is that its results are usually identical to or just slightly higher than those of the PD for the same

\footnotetext{
${ }^{4}$ In the panel debate at the RC28 meeting in Brno, Samuel Lucas, in objecting to the use of the Gini coefficient, made the point that the Gini is scale sensitive. The results differ if the dichotomous education variable is coded 1 and 2,1 and 3, or 12 and 13. In the analysis presented here, the Gini reflects how places of higher education are distributed between classes, and the coding chosen for the education variable does not enter into the calculations. The objection of scale sensitivity does not seem relevant in this case. If, instead of looking at whether a good is obtained (dichotomy), the amount of a good obtained, such as education measured in years of schooling, is considered, then the analysis is of a different distribution; therefore, differences in the results are to be expected.
} 
empirical data. When the proportions compared are close to the extremes of 0 or 1, the Lambda will show much higher values than the PD, approaching plus / minus infinity. If instead the Lambda is kept constant, for example, at 0.20 , this would produce a figure showing the Lambda as a horizontal line and the PD as a curve starting out from values close to 0 when the provision is low, climbing to 0.20 for medium levels of provision, and again sinking towards 0 as the provision of higher education approaches $100 \% .^{5}$

The 'inequality coefficient' (IC) used in Figure 1 is defined as $1-\mathrm{PR}$. The 'participation ratio' is simply the ratio between the proportions obtaining a higher education within two classes. (PR may accordingly also stand for the proportion or probability ratio.) It has also been called the disparity ratio [Saunders 1996]. The PR is identical to another measure of inequality, the ratio of advantage ratios. ${ }^{6}$

When the lowest proportion is used as the denominator of the fraction, the PR varies between 0 (minimum equality where none of the good goes to the less fortunate group) and 1 (maximum equality where the two proportions are equal). The IC accordingly acquires the value 0 , where there is no inequality, and 1 , where inequality is at its maximum.

The horizontal axis in Figure 1 may be interpreted as a time axis, with an increasing provision of higher education over time. The linear PD and the loglinear Lambda are identical or close in value when the proportions compared lie within the range between 0.25 and 0.75 , but show divergent results when the proportions approach the extreme values of 0 or 1 , where the loglinear effects are much stronger than the linear ones. Starting out from proportions with a higher education near zero, the loglinear measures behave similarly to the inequality measures as the provision increases. ${ }^{7}$ The Lambda shows a decreasing association, and the Inequality Coefficient shows decreasing inequality.

\footnotetext{
${ }^{5}$ The PD can be expressed as a function of the Lambda: PD = Lambda *4P(1-P); or - as in Figure 1 - the Lambda can be expressed as a function of the PD: Lambda $=$ PD / 4P(1-P), where $\mathrm{P}$ is the average for the proportion with a high value on the dependent variable (a high education) for the two groups.

${ }^{6}$ The advantage ratio is the proportion of a good obtained by a group, divided by its share of the population, in our case the proportion of positions in higher education obtained by a class, divided by its population share. A ratio of more than 1 indicates a privileged situation, a ratio below 1 correspondingly an underprivileged position. The closer to 1 the RAR - the ratio between these two ratios - is, the more equal the distribution of higher education. The formula for the $\operatorname{RAR}_{\mathrm{L} / \mathrm{H}}$ based on Table 2 is: $\left.[\mathrm{b} / \mathrm{a}+\mathrm{b}) /(\mathrm{b}+\mathrm{d}) / \mathrm{N}\right] /[\mathrm{a} /(\mathrm{a}+\mathrm{b})$ $/(\mathrm{a}+\mathrm{c}) / \mathrm{N}]=\mathrm{b}(\mathrm{a}+\mathrm{c})(\mathrm{a}+\mathrm{b}) \mathrm{N} / \mathrm{a}(\mathrm{b}+\mathrm{d})(\mathrm{a}+\mathrm{b}) \mathrm{N}=[\mathrm{b} /(\mathrm{b}+\mathrm{d})] /[\mathrm{a} /(\mathrm{a}+\mathrm{c})]=\mathrm{P}_{\mathrm{L}} / \mathrm{P}_{\mathrm{U}}=\mathrm{PR}_{\mathrm{L} / \mathrm{U}}$.

7 The OR is in fact sometimes described as the ratio between probabilities, or the PR. However, this is not correct in general. What the OR shows is the ratio between odds, not between proportions. But when the proportions are small the results for the OR are similar to the ratio of proportions. In epidemiological research, use is therefore sometimes made of an interpretation of the OR, referred to as relative risk. 'The odds ratio ... approximates how much more likely (or unlikely) it is for the outcome to be present among those with $x=1$ than among those with $x=0$. For example, if $y$ denotes the presence or absence of
} 
Figure 1. The Lambda coefficient, the 'proportion difference', and the 'inequality coefficient' for comparisons of two groups of equal size, with different levels of provision of higher education (proportions for the binary dependent variable in the two groups lying respectively 0.10 above and 0.10 below the total population level)

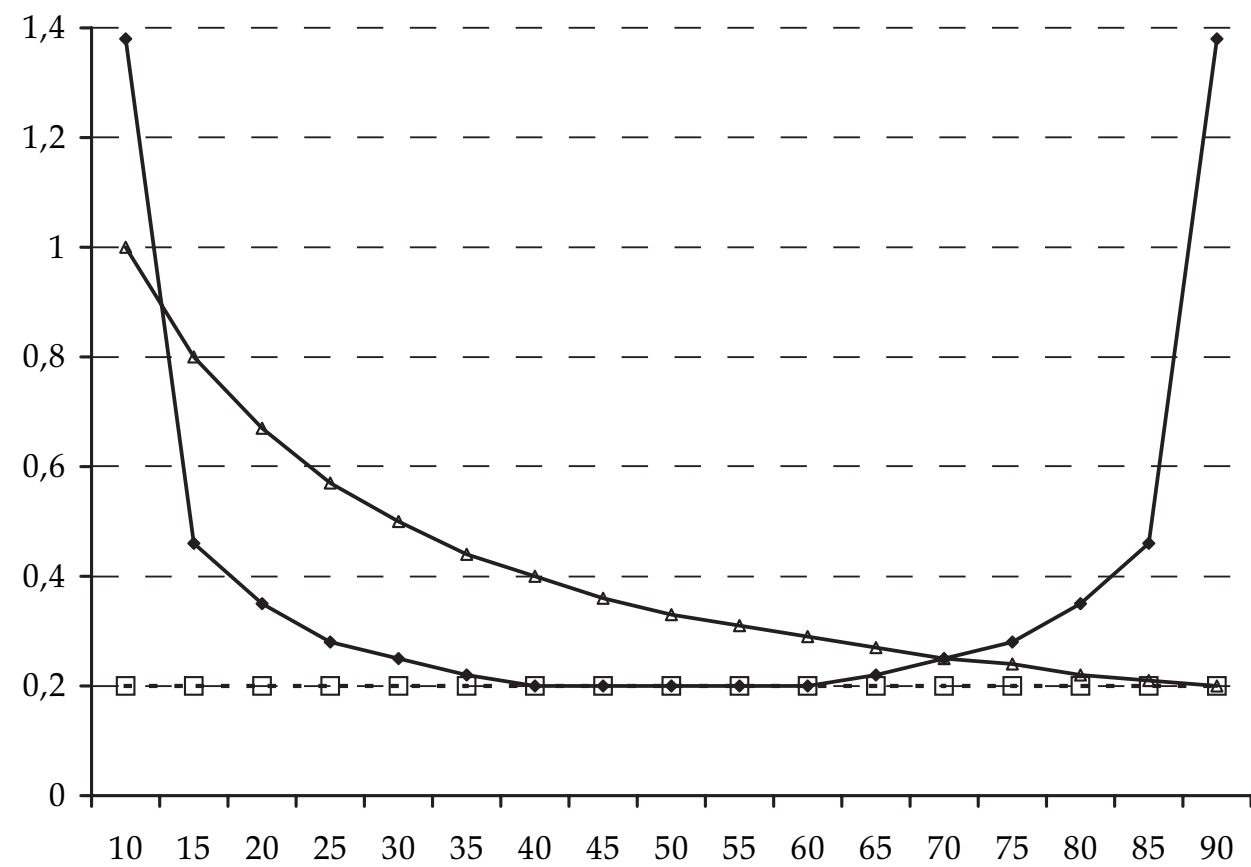

Percentage of the total population with a higher education

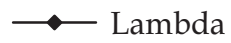

$$
\triangle \quad \begin{aligned}
& \text { Inequality } \\
& \text { coefficient }
\end{aligned}
$$

- $\boxminus$ - Proportion difference

However, this parallel in the trends of the loglinear and inequality measures ceases when we move past the midpoint of $50 \%$ of the population with a higher education and approach $100 \%$. There, according to the Lambda, the association rises, while the IC continues to drop. When, respectively, $80 \%$ and $100 \%$ of the

lung cancer and $x$ denotes whether or not the person is a smoker, then $\psi[\mathrm{OR}]=2$ indicates that lung cancer occurs twice as often among smokers than among nonsmokers in the study population' [Hosmer and Lemeshow 1989]. However, in analyses of survey data, where the phenomena studied often occur more frequently, this interpretation may be misleading. 
population in the two classes obtain a higher education, the Lambda exceeds 1, while the IC with a value of 0.2 reaches its minimum value, given that the gap between the two groups is fixed at 20 percentage points. ${ }^{8}$

The reason for the difference in results is that the loglinear measures, in contrast to the inequality measures, treat the two extremes as identical. For the Lambda it is of no consequence whether the level for higher education is $10 \%$ or $90 \%$. For measures of inequality, however, there is a fundamental difference in meaning between $10 \%$ or $90 \%$ having obtained the good in question. ${ }^{9}$

Also, changes in the class composition of society may affect inequality. Unlike both the linear and loglinear measures of association, as well as inequality measures such as the IC or the PR, the Gini coefficient is also sensitive to changes in the class marginal of the class-by-education table [Hellevik 1997].

\section{The current debate}

A source of disagreement among students of educational attainment has been the question of what causes class inequality. One position is that class differences in success rates reflect 'unfair' practices. In their efforts to obtain a higher education, the lower classes are somehow hindered by various discriminatory practices to which the metaphor of 'the loaded dice of social opportunity' alludes [Halsey 1977: 184]. An alternative interpretation is that the inequality in educational attainment is caused by differences in abilities and efforts [Saunders 1996]. Yet another explanation refers to differences in educational preferences [Murphy 1981, 1990]. The question of causes is of course a very interesting one, but it is not addressed in the Ringen-Hellevik critique of the persistent inequality thesis. Here the issue is how to analyse the class-by-education table, assuming that all those present in the table have the motivation and ability to obtain a higher educa-

\footnotetext{
${ }_{8}$ To calculate the OR and the Lambda in the extreme case, the proportions 99.9 and 79.9 at one end of the axis and correspondingly 20.1 and 0.1 at the opposite end of the axis were used, which gives a Lambda of 1.38 .

9 An objection to the inequality coefficient was raised at the RC28 Brno meeting by LoisAndre Vallet, who pointed out that the trend for the results of the inequality coefficient will be different if, instead of higher education, we look at the distribution of lower education. However, this should not be considered a paradox or a problem. If we calculate the proportion ratio for low education, by taking the ratio of $\mathrm{P}_{\text {Upper }} / \mathrm{P}_{\text {Lower }}$ (the upper class in this case being the 'underprivileged' one), the curve will show a pattern exactly inverse to that of the PR for higher education. In other words, the less inequality in the distribution of higher education, the more inequality we get in the distribution of lower education. In the latter case, the horizontal axis shows a declining provision of lower education from left to right. The change in tendency is thus a consequence of the change in the distribution under consideration, either that of higher or lower education. For measures of inequality it is the distribution of the preferred position, in this case higher education, that is the focus of interest.
} 
tion. Such an assumption seems to underlie much of the educational attainment research.

New research on the relationship between class and education has found that it is no longer a stable relationship, and according to a recent review, in several countries there are now trends of a decreasing association between class and educational attainment [Breen and Jonsson 2005]. ${ }^{10}$ This of course weakens the persistent inequality thesis and implies an even steeper reduction in inequality according to inequality measures. However, whether the class-education association is in fact stable or decreasing is of no consequence for the disagreement over how inequality in educational attainment should be measured.

Ringen [1997] and Hellevik [1997] are not the first to have suggested that measures of inequality be used to describe inequality in educational attainment. Among earlier examples are Glennerster and Low, who found decreasing advantage ratios for privileged groups and a corresponding increase for the underprivileged in Britain, concluding that '... the reforms of the 1960s, are having their effect in the 1970s and 1980s' [1990: 76]. Another example is Saunders [1996], who uses what he calls a disparity ratio. This, as mentioned above, is the same as the proportion ratio. Saunders finds that this ratio shows a decline in class inequality over time in Britain.

Of particular relevance to the topic of this paper is John Logan's criticism [1996] of the use of the concept of 'margin insensitivity' in mobility research. His arguments, which I will return to below, seem thus far to have been overlooked by students of class inequality. The same must be said of the Ringen-Hellevik critique. The review by Breen and Jonsson [2005] of recent developments in this field does not mention alternative approaches to measuring inequality and the consequent divergence in results. In a debate in Acta Sociologica there was an exchange of opinions between Marshall and Swift [1999, 2000] and Kivinen, Ahola and Hedman [2001, 2002] on the one hand and Ringen [2000] and Hellevik [1997, $2000,2002]$ on the other. There have also been other contributions to the debate critical of the use of loglinear measures to describe inequality [Lampard 2000; Marks 2004]. The debate at the May 2007 meeting of the Research Committee on Social Stratification and Mobility of the International Sociological Association (RC28) in Brno, Czech Republic, provided an opportunity for further exchanges on this matter.

The answers Marshall and Swift [1999, 2000] gave in Acta Sociologica seem to accept that the distribution of higher education among classes has indeed become less unequal. But they propose that inequality of distribution is just one particular kind of inequality. Another and more interesting kind is captured by loglinear measures. They claim that the loglinear association approach is supe-

\footnotetext{
${ }^{10}$ In the panel debate at the RC28 meeting in Brno, this point was made by Michael Hout, who also made several references to older publications reporting reduced association and criticised Ringen and Hellevik for not being sufficiently acquainted with this literature.
} 
rior because it captures something essential - namely, the bias in the allocation mechanism itself - a bias that appears to be highly persistent over time in most countries. The basis for this claim is the idea that loglinear measures are 'margin insensitive'. Criticism of this idea was restricted to an endnote in my first article [Hellevik 1997: 394]. My experiences from the debate so far have convinced me that the disagreement concerning the special properties of loglinear measures is a core issue, making it difficult to reach an agreement with regard to the status of inequality in educational attainment.

\section{The idea of margin insensitivity}

When either the provision of higher education or the class composition of society changes, this supposedly does not affect the association shown by the loglinear measures. These measures are said to capture the effect 'net of' such changes in the marginals of the class-by-education table, thus reflecting the 'true nature' of the allocation mechanism. The pattern of stable association and decreasing inequality is accordingly interpreted as a result of a stable allocation mechanism working within a changing framework of increasing provision.

In his seminal article on the idea of margin insensitivity in the analysis of class and educational attainment, Mare writes: 'Under the logistic response model, differences in background effects, either over school transitions or over cohorts, cannot result from changing marginal distributions of either independent or dependent variables because such changes do not affect the [loglinear measure]'. Since the loglinear measures are 'invariant under changes in the marginal distributions of the variables', they give 'true effects' [Mare 1981: 75]. Similar statements abound in later contributions to the educational attainment literature: 'In addition because the Mare model is based on the odds ratio, which is insensitive to marginal distributions, the parameters of the model are unaffected by aggregate expansion or contraction of the educational system' [Breen and Jonsson 2000: 758]. 'This [logit analysis] will ensure that we focus on measuring the mechanism behind the distribution of education across class backgrounds - our estimates will not be confounded if there is an overall increase (or decrease) in the general transition probabilities' [Erikson and Jonsson 1996: 75]. The loglinear measures are described as 'margin free' [Grusky and Tienda 1993: vii], and as 'revealing the "pure" association between origin characteristics and educational attainment' [Breen and Jonsson 2005: 225]. The use of the loglinear model is hailed as a methodological breakthrough, making it '... possible to specify the intrinsic association between variables after purging out nuisance variability in marginal distributions' [Grusky and Tienda 1993: vii].

The idea of margin insensitivity seems to have emerged from a statistics textbook [Bishop, Fienberg and Holland 1975], which is the only reference given in central texts such as Mare [1981: 74] and Erikson and Goldthorpe [1992: 56]. 
Table 2. Class and education: row and column multiplication by, respectively, $X$ and $Y$

\begin{tabular}{lcccccc}
\hline & \multicolumn{3}{c}{ Before multiplication } & \multicolumn{3}{c}{ After multiplication } \\
& $\begin{array}{c}\text { Upper } \\
\text { class }\end{array}$ & $\begin{array}{c}\text { Lower } \\
\text { class }\end{array}$ & SUM & $\begin{array}{c}\text { Upper } \\
\text { class }\end{array}$ & $\begin{array}{c}\text { Lower } \\
\text { class }\end{array}$ & SUM \\
\hline High education & $\mathrm{a}$ & $\mathrm{b}$ & $\mathrm{a}+\mathrm{b}$ & $\mathrm{XYa}$ & $\mathrm{Yb}$ & $\mathrm{Y}(\mathrm{Xa}+\mathrm{b})$ \\
Low education & $\mathrm{c}$ & $\mathrm{d}$ & $\mathrm{c}+\mathrm{d}$ & $\mathrm{Xc}$ & $\mathrm{d}$ & $\mathrm{Xc}+\mathrm{d}$ \\
\hline SUM & $\mathrm{a}+\mathrm{c}$ & $\mathrm{b}+\mathrm{d}$ & & $\mathrm{X}(\mathrm{Ya}+\mathrm{c})$ & $\mathrm{Yb}+\mathrm{d}$ & \\
\hline
\end{tabular}

Before: $\quad \mathrm{OR}=(\mathrm{a} / \mathrm{c}) /(\mathrm{b} / \mathrm{d})=\mathrm{ad} / \mathrm{bc}$

After: $\quad \mathrm{OR}=(\mathrm{XYa} / \mathrm{Xc}) /(\mathrm{Yb} / \mathrm{d})=\mathrm{XYad} / \mathrm{XYbc}=\mathrm{ad} / \mathrm{bc}$

Before: $\quad P D=a /(a+c)-b /(b+d)$

After: $\quad \mathrm{PD}=\mathrm{XYa} / \mathrm{X}(\mathrm{Ya}+\mathrm{c})-\mathrm{Yb} /(\mathrm{Yb}+\mathrm{d})=\mathrm{Ya} /(\mathrm{Ya}+\mathrm{c})-\mathrm{Yb} /(\mathrm{Yb}+\mathrm{d})$

Other texts refer to Mare [1981] or give no references at all. Bishop, Fienberg and Holland [1975: 14] say that the odds ratio (called the cross product ratio) is 'invariant under row and column multiplications'. If we multiply columns and/or rows with constants (different from 0), this does not change the OR, even though the marginals of the table will change. Table 2 illustrates what this means. In the cells of the left column, frequencies $a$ and $c$ have been multiplied by $X$, and in the cells of the upper row, $a$ and $b$ have been multiplied by $Y$. This produces a change in the marginals; for instance, an increase in the proportion with a higher education in the population, and in the proportion with a high status background. The formula for the OR shows why this measure and other measures derived from it are unaffected by row/column multiplication with constants. The constants appear in the nominator as well as the denominator of the fraction and are thus cancelled out. Also, the proportion difference is unaffected by multiplication by $X$ in cells with the same value on the independent variable (i.e. columns in table 2). Changes in the distribution of the independent variable from multiplication by a constant do not alter the result for the PD. But row multiplication in Table 2, which changes the distribution on the dependent variable, affects the linear measure of association.

In Table 3 this is illustrated with numbers. The frequencies for higher education in the first row are multiplied by 3 and those for lower education in the second row by 0.5 . This brings the level of education in the population up from $25 \%$ to $67 \%$. The marginal distribution of the class variable is also altered (the percentage for 'upper' class increases from 50 to 67). For the PD the row multiplication produces a modest change in the results (from $0.4-0.1=0.3$ to $0.8-0.4=0.4$ ). The OR remains unchanged: $(40 / 60) /(10 / 90)=6$ before, and $(120 / 30) /(30 / 45)=6$ after the multiplication, with a Lambda of 0.45 in both cases. 
Table 3. Class and education: example where the first row is multiplied by 3 and the second row by 0.5

\begin{tabular}{lcccccc}
\hline & \multicolumn{3}{c}{ Before multiplication } & \multicolumn{3}{c}{ After multiplication } \\
& $\begin{array}{c}\text { Upper } \\
\text { class }\end{array}$ & $\begin{array}{c}\text { Lower } \\
\text { class }\end{array}$ & SUM & $\begin{array}{c}\text { Upper } \\
\text { class }\end{array}$ & $\begin{array}{c}\text { Lower } \\
\text { class }\end{array}$ & SUM \\
\hline High education & 40 & 10 & 50 & 120 & 30 & 150 \\
Low education & 60 & 90 & 150 & 30 & 45 & 75 \\
\hline SUM & 100 & 100 & 200 & 150 & 75 & 225 \\
\hline
\end{tabular}

What are the implications of all this? What the statisticians say is precise and clear - no change in OR when columns and/or rows of the table are multiplied by a constant - an operation that also changes the marginal distributions. However, in the educational attainment literature, this statement has been given a much wider and unfounded interpretation. We have a logically untenable deduction, from insensitivity in relation to one specific kind of change in the marginals to the claim that the OR is insensitive to marginal changes in general. But if, for instance, we were to multiply the frequency in just one of the cells with a constant, then the marginal distributions and the OR would both be altered. For all kinds of marginal changes that are not the result of column and/or row multiplication with constants, it is difficult to see what could be the meaning of the concept of 'margin insensitivity'.

If the claim of the margin insensitivity of loglinear measures must be abandoned, the proposition that these measures should be used to describe bias in allocation mechanisms is undermined. However, the experience in the debate so far is that those who believe that there is such a thing as margin insensitivity are not easily persuaded otherwise. Therefore, a series of arguments against the use of loglinear measures as indicators of bias in allocation mechanisms are presented below.

\section{A different trend for mechanism and outcome?}

Is it possible that, as proposed by Marshall and Swift [1999], the bias in the allocation mechanism may develop differently from the inequality in the allocation outcome? Owing to the extreme complexity of the process of recruitment to higher education, none of the participants in the debate have attempted to specify in any detail the concrete nature of the mechanisms involved in allocating educational positions. In most analyses the mechanisms are treated as black boxes, and 
conclusions about their unknown contents are based on the outcome as shown in the class-by-education table.

If the 'fairness' of the allocation mechanism is something that has to be inferred from the results it produces, a divergence with regard to bias in mechanism and outcome should not be possible. It would seem self-evident that inferences about stability or change in bias of the unknown allocation mechanisms must be based on information of stability or change in the inequality of the distributional outcome of the allocation process. A straightforward objection to the MarshalSwift proposition is therefore that it does not make sense to suggest that the bias in the allocation mechanism may be stable at the same time as the inequality in the allocation outcome is decreasing.

\section{The difference between loglinear and linear measures}

The belief that loglinear measures are margin insensitive manifests itself in descriptions of a fundamental difference in substantive meaning between loglinear and linear measures of association. (No comparisons with measures of inequality are made, as they are hardly mentioned at all in the literature on educational attainment.) In his 1981 article Mare makes the following distinction between linear and loglinear measures:

Simple differences in proportions continuing in school among background groups change over cohorts primarily in response to the average level of proportions, rather than in response to changes in the principles by which schooling is allocated. By contrast, statistical models that measure the association between school continuation and social background, net of the marginal distribution of schooling, [i.e. loglinear measures] are sensitive to changes in the principles by which schooling is allocated and not to changes in the dispersion of the schooling distribution. [Mare 1981: 83]

The claim that loglinear and linear measures capture quite different aspects of the allocation process is undermined when we take into consideration how similar, in most instances, the results given by the two kinds of measures are. There is no difference at all in their results when the distribution of the independent variable (the class composition of society) changes. Also, if the distribution of the dependent variable (education) changes, there is little or no difference in results for loglinear and linear measures as long as the proportions compared lie within the interval of 0.25 to 0.75 .

We may thus have a society undergoing all kinds of changes with regard to its class composition, and also have a dramatic increase in the level of higher education, for instance from $35 \%$ to $65 \%$ for the total population, without there being any noticeable difference in results between the linear proportion difference and 
the loglinear Lambda. The suggestion that there is a fundamental difference in substantive meaning between the two kinds of statistical measures is clearly not tenable within a 'normal' range of variation for the level of higher education in a society.

The important distinction is thus not the one between linear and loglinear measures, but rather the one between the measures of association on the one hand and the measures of inequality on the other.

\section{Loglinear measures and bias in the allocation mechanism}

As illustrated in Figure 1, it is when provision reaches high levels that the trends shown by loglinear and inequality measures diverge. By using the fictitious example of an extremely high level of provision, it becomes clear that it makes little sense to suggest that it is the loglinear measures, rather than measures of inequality, that capture bias in allocation mechanisms. ${ }^{11}$

Imagine a nation where $99.99 \%$ of the upper class and $99.90 \%$ of the lower class attains higher education. The participation ratio is 0.999 and the inequality coefficient accordingly 0.001 , indicating that higher education positions are distributed between classes nearly as evenly as possible. The distribution on class for those with higher education is representative of the population since the two groups are practically identical. But according to loglinear measures $(\mathrm{OR}=$ $[99.99 / 0.01] /[99.9 / 0.1]=9999 / 999=10$ and Lambda $=0.58)$, the mechanism for allocating higher education positions is severely biased in this case.

In fact, if the prior situation had been that $75 \%$ of the upper class obtained a higher education and only $25 \%$ of the lower class, this would have represented a less biased allocation mechanism according to the loglinear measures $(\mathrm{OR}=$ $[75 / 25] /[25 / 75]=3 / 0,333=9$ and Lambda 0.55). In contrast, inequality measures indicate a much more unequal distribution: At Time 1, IC is 0.667 as compared to 0.001 at Time 2 .

To suggest that we have an extremely biased allocation mechanism when a good is provided to nearly everyone in both classes does not seem very meaningful. The reason for the counterintuitive result is that the loglinear measures do not distinguish between getting and not getting a good, the values of the education variable are treated symmetrically. What actually is very unequally distributed at Time 2 is the case of not having obtained a higher education (0.10 as compared to 0.01). The rationale behind measures of inequality, however, is that the values of the variable in question are seen as asymmetric; they may be ranked according to attractiveness. $^{12}$

${ }_{11}$ A problem that we will not go into here is the question of the devaluation of higher education; that is, the extent to which the value of obtaining a higher education is dependent on the number of people obtaining one.

12 Cf. note 9 . 
Figure 2. Fictitious examples of class-education relationships

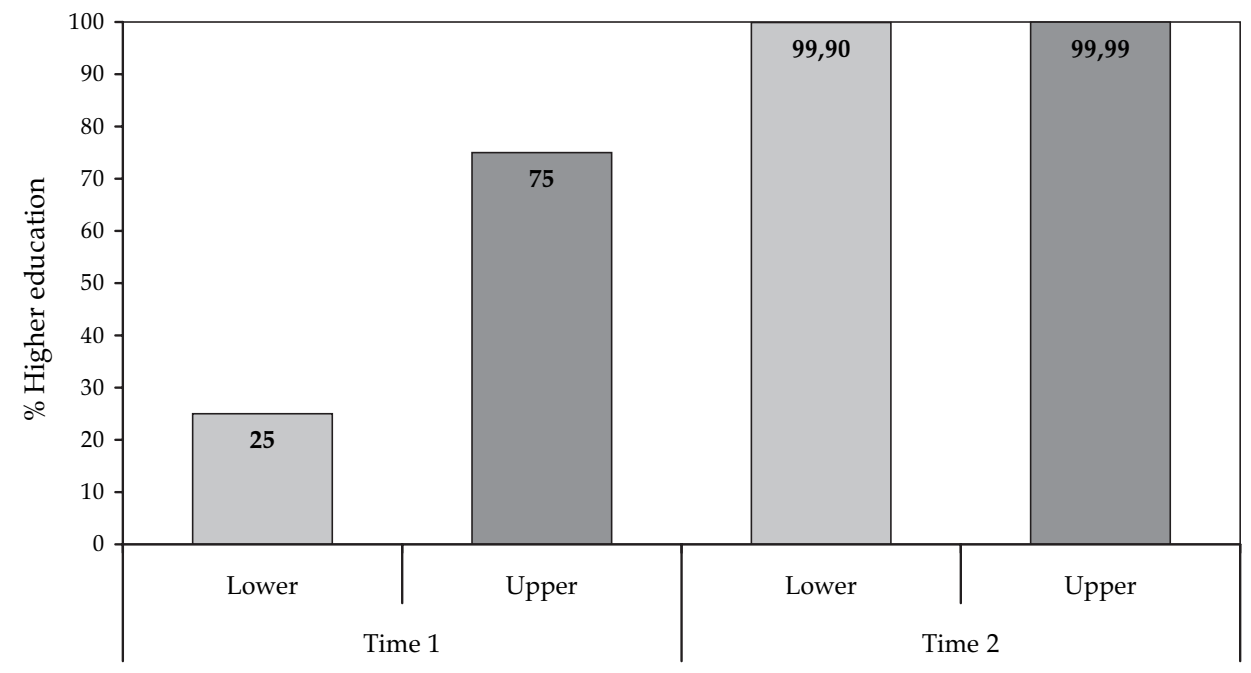

The contrast in Figure 1 between the monotonously decreasing inequality shown by the IC and the pattern of the first decreasing and then increasing association according to Lambda, as the provision of higher education increases in such a way that a constant gap between the classes is preserved, demonstrates how the two kinds of measures react differently to changes in the level of provision. Figure 2 provides an example where it goes against common sense to claim that loglinear measures rather than inequality measures capture the degree of bias in the allocation mechanism.

\section{Models of allocation mechanisms}

Another way of comparing the ability of loglinear and inequality measures to capture mechanism bias is to construct a theoretical model of the recruitment process that gives independent indicators of bias in the allocation process. Even if such a model fails to capture the complexity of the real processes, it should at least come closer to reality than the model of 'row and column multiplication with a non-zero constant' which is the basis of the margin insensitivity thesis.

Earlier in the debate sampling models were suggested as being a simple representation of the allocation process, with quota sampling and stratified random probability sampling proposed_as alternatives [Hellevik 1997: 390, 2000: 83]. Table 4 shows an example of an increase of 40 percentage points in the level of higher education in both classes. The PD and the OR/Lambda show a stable as- 
sociation between class and education, and the PR/IC shows decreasing inequality over time. To simplify calculations, the two classes are assumed to be of equal size.

The question now is what the two sampling models, each representing a possible, if not very realistic, process of recruitment to higher education that could have produced the results shown in Table 4, will tell us about bias in the allocation mechanism. Is the bias stable, as Marshall and Swift [1999] would infer from the stable loglinear measures? Or is there less mechanism bias at Time 2, as the inequality measures suggest?

If we imagine that recruitment to higher education is done by means of quota sampling, the quotas are clearly biased at Time 1, since the upper class gets more and the lower class less than what corresponds to their shares of the population. The quotas at Time 2 are less biased since, to produce the results in the table, they must have been fixed so as to make the social composition of the sample more similar to the 50-50 distribution on classes in the population. The sample distribution has changed from 67-33 at Time 1 to 57-43 at Time 2. If we regard the additional positions of higher education allocated at Time 2 as a new quota sample, added to the original one with a 67-33 distribution, the composition of the additional sample is proportionate to the population distribution (50-50). The allocation of the 'new' positions amongst classes is unbiased since it reflects the class composition of society.

Either way, the conclusion from the quota sampling model is clear: There is a change in the selection mechanism (the quota distribution) that makes it less biased at Time 2 than it was at Time 1. In other words, the trend of mechanism bias is the same as the trend of outcome inequality shown by inequality measures. Both show decreased inequality/bias, in contrast to the stable results shown by the loglinear and linear measures of association.

If we instead use stratified random sampling as a selection model, bias in the mechanism may be defined as disproportionality, which is indicated by the difference between the sampling fractions within the two classes. However, this difference may be described in two ways: as the absolute difference, or as the ratio between the fractions. The first is the same as the proportion difference (PD), the second the same as the proportion ratio (PR). Thus we are back where we started, forced to choose between measures of association and inequality to describe selection bias.

However, there is a criterion for determining the degree of bias in the sampling procedure that may solve the question of change or stability in the selection mechanism. With a disproportionate sample, weighting is used to restore representativity. The weights are calculated as the ratio between a group's share of the population and its share of the sample. The closer the weights are to the value 1 , the less bias there is in the sampling procedure that has to be corrected through weighting. Table 4 shows that the weights needed at Time 1 to correct for sampling bias are further away from unity than the weights at Time 2 . This 
Table 4. Two sampling models for recruitment to higher education (classes of equal size)

\begin{tabular}{|c|c|c|c|c|c|}
\hline \multirow[b]{2}{*}{ Class: } & \multicolumn{2}{|c|}{ Time 1} & \multicolumn{2}{|c|}{ Time 2} & \multirow{2}{*}{$\begin{array}{l}\text { Conclusion with re- } \\
\text { gard to change } \\
\text { from Time } 1 \text { to } 2\end{array}$} \\
\hline & Lower & Upper & Lower & Upper & \\
\hline$\%$ higher education & 20 & 40 & 60 & 80 & \\
\hline Proportion difference H-L & \multicolumn{2}{|c|}{0.20} & \multicolumn{2}{|c|}{0.20} & Stable association \\
\hline Odds & 0.25 & 0.67 & 1.50 & 4.00 & \\
\hline Odds ratio $\mathrm{H} / \mathrm{L}$ & \multicolumn{2}{|c|}{2.67} & \multicolumn{2}{|c|}{2.67} & Stable association \\
\hline Lambda & \multicolumn{2}{|c|}{0.25} & \multicolumn{2}{|c|}{0.25} & Stable association \\
\hline Participation ratio: $\mathrm{L} / \mathrm{H}$ & \multicolumn{2}{|c|}{0.50} & \multicolumn{2}{|c|}{0.75} & Increased equality \\
\hline Inequality coefficient ( 1 - PR) & \multicolumn{2}{|c|}{0.50} & \multicolumn{2}{|c|}{0.25} & Reduced inequality \\
\hline$\%$ quota of sample & 33 & 67 & 43 & 57 & Reduced selection bias \\
\hline$\%$ additional quota at time 2 & - & - & 50 & 50 & Reduced selection bias \\
\hline Sampling fraction & 0.2 & 0.4 & 0.6 & 0.8 & \\
\hline Difference in sampling fractions & \multicolumn{2}{|c|}{0.2} & \multicolumn{2}{|c|}{0.2} & \\
\hline Ratio of sampling fractions & \multicolumn{2}{|c|}{0.5} & \multicolumn{2}{|c|}{0.75} & \\
\hline $\begin{array}{l}\text { Weights needed to make sample } \\
\text { representative of population }\end{array}$ & 1.52 & 0.75 & 1.16 & 0.88 & Reduced selection bias \\
\hline
\end{tabular}

is no surprise, since the ratio of the sampling weights in fact corresponds to the participation ratio.

The two models are extremely simple, and of course are nowhere near a realistic representation of the actual recruitment processes. Nevertheless, they are realistic in the sense that they could have produced the results found in empirical studies of class differences in educational attainment. What both models show is that when the outcome of the allocation process becomes less unequal, the selection mechanism is less biased, according to the composition of the quotas and the sampling weights. It is thus measures of inequality, and not loglinear measures, that capture the trend for bias in the allocation mechanisms.

In an article from 1996, John Logan developed another allocation model, a two-sided logit model (TSL), derived from a random matching model of oppor- 
tunity, for the matching of individuals to jobs. He defined an explicit set of rules of access and was thereby able to test, through simulations, the effect of changes in demand (job offers) on loglinear measures. His concludes:

Margin insensitivity - the ability to multiply rows and columns without affecting odds ratios - does not guarantee demand insensitivity, the ability of parameters to measure the rules of access without being affected by shifts in demand. Loglinear models possess the former but not the latter property, while the situation is reversed for TSL models. [Logan 1996: 176]

Those who continue to insist that loglinear measures reflect bias in the selection procedures face the challenge of arguing against the relevance of the above models, and of establishing counter-examples in the form of models in which the distribution of higher education may become more equal at the same time as the bias in the allocation mechanism remains unchanged. This challenge was made early on in the debate [Hellevik 2000], but so far no one has taken it up.

\section{The relationship between provision and outcome inequality}

Will increased provision necessarily reduce inequality, and is the expansion of higher education a sufficient explanation for the observed reduction of inequality in the distribution of higher education positions between classes? With regard to social mobility, an increase in the number of high status positions means that there will necessarily be some upward mobility in order for these positions to be filled. For recruitment to higher education, there will similarly be a restriction on the outcome if the increase in provision of higher education positions exceeds what can possibly be absorbed by the upper class. In Table 4 , where provision of higher education increases by 40 points from $30 \%$ to $70 \%$ for the whole population, the percentage with a higher education in the lower class must necessarily increase from $20 \%$ to at least $40 \%$, since the upper class can at most absorb threequarters of the increased provision between Time 1 and Time 2 before the $100 \%$ ceiling is reached.

However, within the limits set by this restriction, any outcome is possible. The 'new' positions at Time 2 may in theory all have gone to the lower class, making it the privileged class with regard to higher education $(100 \%$ attainment compared to $40 \%$ for the upper class). A more realistic outcome may be the same relative increase for both classes, which would have meant percentages for higher education of $47 \%$ in the lower and $93 \%$ in the upper class at Time 2 . In this case, association according to the percentage difference and Lambda would have increased (from 0.20 and 0.25 to 0.46 and 0.68 , respectively), while the inequality would have been the same as at time 1 according to the PR/IC. In this case the two sampling models would have shown the bias in the allocation mechanism to 
be stable (we would have had the same quota distributions or sampling weights at Time 1 and Time 2).

An increase in provision does not in itself guarantee that the distribution of higher education will become less unequal (except for possible ceiling effects). If the same sampling models had been used as mechanisms for allocating education positions at Time 2 as at Time 1, the inequality of the outcome would have remained the same even with a dramatically increased provision. The reduced inequality in Britain shown in Table 1 is thus the result of a change in the bias of the allocation mechanisms. Without this change, the inequality of the outcome would not have been reduced. The increase in the provision of higher education may, however, have facilitated such a change in the mechanism bias. It may for instance have been easier for the upper class to accept a development which meant a deterioration of its privileged position in the education system, since members of this class also experienced increased access to higher education.

Actual developments in many countries in the second half of the 20th century, that is, a parallel increase in the percentage of people attaining higher education in different classes, may have been experienced as 'fair' in the sense that the additional positions were distributed proportionately according to the population share of the classes. Without an increase in provision, a reduction of bias in the allocation mechanism would have been less likely to occur, since this would then have required a loss in the number of higher education positions for the upper class. Increasing provision makes it possible for egalitarian reforms to achieve their goals with less risk of producing social tensions and conflicts. But increased provision will not necessarily in itself lead to a more equal distribution of higher education positions.

In the literature in which the development of class inequality in educational attainment is described as stable, we find quite the opposite interpretation of the consequences of growth in educational opportunities. The expansion of higher education is seen as the reason that the lower class and their political representatives have accepted stable inequality (which actually, as we have argued, is stable association and not inequality):

As long as the educational attainment of lower social strata is rapidly increasing, political attention can neglect any parallel increases among the privileged classes. Thus, educational expansion can alleviate political pressure to reduce inequalities.

... Thus the modernization theorists' hypothesis that educational expansion results in greater equality of educational opportunity must be turned on its head: expansion actually facilitates to a large extent the persistence of inequalities in educational opportunity. [Blossfeld and Shavit 1993: 22]

If in fact, as I have argued, class inequalities of educational opportunity have been reduced over the past decades, a development probably facilitated by educational expansion, the hypothesis of the modernisation theorists is not rejected but rather supported by the empirical results. 


\section{Moderate and radical reform strategies}

As a final effort to make the point that increasing provision combined with a stable association means reduced inequality, rather than stable inequality, as students of educational attainment seem to think, an example from a less complex allocation process will be used, namely that of wage negotiations. The goal of an egalitarian income policy would be to reduce the inequality produced by unequal wage allocation in the past. Without an expanding economy, a policy to transfer income from high- to low-income groups would be necessary to reduce inequality, a policy bound to produce conflicts. With more income to distribute than in previous years, one might choose a radical egalitarian strategy of compensatory wage increases that reverses the past pattern of bias. However, giving high-income groups a smaller nominal wage raise than low-income groups would probably meet with fierce opposition from the privileged strata. Changing to a non-biased distribution of wage increases, that is, giving the same absolute raise to all, would be an example of a moderate egalitarian reform more likely to be accepted as fair by all groups.

That even the moderate strategy of giving the same wage increase to all groups is egalitarian in its consequences is reflected in the strategies of the parties in wage negotiations. Equal absolute raises are demanded by unions campaigning for an egalitarian outcome, while unions representing high-income workers will fight to preserve their present privileges by insisting on the principle of equal relative increases. The strategy of equal absolute raises means preserving the absolute wage differences (the association between occupation and income as measured by a regression coefficient will be stable), but by raising the wage level for all occupations the inequality-generating effect of the constant income gap is gradually reduced, as shown by the wage ratio or the Gini coefficient for the income distribution.

Similar points of view are found in the literature on income redistribution. It is well known that a uniform income transfer will have a strongly equalising effect on the final distribution of income even though absolute income differentials are left unaffected, and even though the statistical association between the primary and the final distribution of income remains constant (perfect rank-correlation) [Lambert 1993]. The same holds for benefits in kind that are sometimes made uniformly available to the general population [see Aaberg 1984].

\section{Conclusion}

There are several reasons why this discussion of trends in educational attainment is more than just nitpicking over methodological subtleties. No one can deny the important theoretical and practical implications of the topic. Basic structural aspects of modern societies and the ability of their political institutions to alter them are disputed. This makes it all the more remarkable that views continue to 
differ so sharply over what actually occurred during the second half of the 20th century with regard to class inequality in recruitment to higher education and the effects of egalitarian educational reforms.

Stein Ringen and I have argued that students of educational attainment have misinterpreted their own empirical data, because they have not distinguished between measures of association and measures of inequality. The statistical association between class and education may have been relatively stable, but this stability, in combination with a rising level of education in the population, means that the inequality in the distribution of higher education has been markedly reduced over time. Those from the new cohorts who attain higher education are more representative of their societies than the highly educated in prior generations were of theirs. This is a result of reduced bias in the allocation mechanisms, most likely facilitated by the increasing provision of higher education. Decreasing inequality means that the conclusion in the literature that egalitarian educational reforms are ineffective is empirically unfounded.

The discussion is also a reminder of how important it is to choose statistical measures that correspond to the purpose of the analysis, measures that actually capture what the researcher wants to describe. However, up to now it has been surprisingly difficult to find acceptance for the suggestion that measures of inequality, rather than loglinear measures of association, should be used to analyse inequality.

One problem may be that loglinear measures are relatively complicated, and their characteristics perhaps not always fully understood, even by those who use them. This has lead to the widespread but unfounded belief that loglinear measures are margin insensitive in a general sense, reflecting association net of changes in class composition and educational provision, so as to capture bias in the allocation mechanism.

Considering how central the concept of inequality is to the study of class differences in educational attainment, it is puzzling that the statistics called 'measures of inequality' have been more or less overlooked in the literature. One reason for not considering alternatives to the preferred approach, of course, is the firm if unjustified belief in the 'margin insensitivity' of loglinear measures. It is also possible that measures of inequality have not been considered simply because they are less well known and less often used than measures of association in sociology. For instance, they are rarely mentioned in statistical textbooks for sociologists, in contrast to textbooks for political scientists. ${ }^{13}$

There were indications in the debate at the RC28 meeting in Brno in 2007 that a reconsideration of positions may be under way. John Logan presented his

${ }^{13}$ Some early examples of statistics textbooks for political science that discuss measures of inequality such as the Gini Coefficient/Index are Alker [1965], Benson [1969], Hellevik [1971], and Leege and Francis [1974]. In contrast the Gini is not mentioned in Blalock's classic sociology text [1960], nor in Galtung [1967], or Iversen [1979]. 
critique of the margin insensitivity claim in its extended version and said that he hoped never to hear that claim repeated in the future. Yossi Shavit, in his presentation for the plenary session, wrote that it has been a mistake to regard educational expansion as a 'nuisance' to be adjusted for, and suggested that it be brought back into the recruitment models instead of being ignored. ${ }^{14}$ One way of doing this is to make use of inequality measures, as suggested by Stein Ringen and myself.

OtTAR HeLLEVIK is a professor of political science at the University of Oslo. He has written several textbooks and articles on methodology and statistics (the most recent being 'Linear versus Logistic Regression When the Dependent Variable is a Dichotomy', to appear in Quality \& Quantity; electronically pre-published). His main research interests are value changes ('Age Differences in Value Orientation - Life Cycle or Cohort Effect?', International Journal of Public Opinion Research 14: 286-302) and subjective wellbeing ('Economy, Values and Happiness in Norway', Journal of Happiness Studies 4: 243-283).

\section{References}

Aaberg, R. 1984. 'Market-independent Income Distribution: Efficiency and Legitimacy.' Pp. 209-230 in Order and Conflict in Contemporary Capitalism, edited by J. Goldthorpe. Oxford: Oxford University Press.

Alker, H. R., Jr. 1965. Mathematics and Politics. New York: The Macmillan Co.

Benson, O. 1969. Political Science Laboratory. Columbus, Ohio: Charles E. Merrill Publishing Co.

Bishop, Y. M. M., S. E. Fienberg and P. W. Holland. 1975. Discrete Multivariate Analysis. Cambridge: MIT Press.

Blalock, H. M. 1960. Social Statistics. New York: McGraw-Hill \& Co.

Blossfeld, H.-P. and Y. Shavit. 1993. 'Persisting Barriers. Changes in Educational Opportunities in Thirteen Countries.' Pp. 1-23 in Persistent Inequality. Changing Educational Attainment in Thirteen Countries, edited by Y. Shavit and H.-P. Blossfeld. Boulder: Westview Press.

Breen, R. and J. O. Jonsson. 2000. 'Analyzing Educational Careers: A Multinomial Transition Model.' American Sociological Review 65: 754-772.

\footnotetext{
${ }^{14}$ Quotes from the PowerPoint presentation by Yossi Shavit, Meir Yaish and Eyal Bar Haim for the plenary session at the Brno RC28 meeting, posted at the conference website: 'Despite the importance of educational expansion in the public and theoretical debate concerning IEO, it is usually ignored by empirical research. Rather, it is treated as a nuisance to be adjusted for' (From slide 5). 'Effective egalitarian educational policy increases participation (expansion). However, much of our collective work ignores expansion and thus, misses an important beneficial outcome. Let's bring expansion back into our models' (From slide 26 - the final one).
} 
Breen, R. and J. O. Jonsson. 2005. 'Inequality of Opportunity in Comparative Perspective: Recent Research on Educational Attainment and Social Mobility.' Annual Review of Sociology 31: 223-243.

Erikson, R. and J. H. Goldthorpe. 1992. The Constant Flux. A Study of Class Mobility in Industrial Societies. Oxford: Clarendon Press.

Erikson, R. and J. O. Jonsson. (eds.) 1996. Can Education be Equalized? Boulder, CO: Westview.

Galtung, J. 1967. Theory and Methods of Social Research. Oslo: Universitetsforlaget.

Glennerster, H. and W. Low. 1990. 'Education and the Welfare State: Does It Add Up?' Pp. 28-87 in The State of Welfare. The Welfare State in Britain since 1974, edited by J. Hills. Oxford: Clarendon Press.

Grusky, D. B. and M. Tienda. 1993. 'Foreword.' Pp. vii-viii in Persistent Inequality. Changing Educational Attainment in Thirteen Countries, edited by Y. Shavit and H.-P. Blossfeld. Boulder: Westview Press.

Halsey, A. H. 1977. 'Towards Meritocracy? The Case of Britain.' Pp. 173-186 in Power and Ideology in Education, edited by J. Karabel and A. H. Halsey. Oxford: Oxford University Press.

Heath, A. F. and P. Clifford. 1990. 'Class Inequalities in Education in the Twentieth Century.' Journal of the Royal Statistical Society, Series A 153: 1-16.

Hellevik, O. 1971. Forskningsmetode $i$ sosiologi og statsvitenskap. (Research Methods in Sociology and Political Science) Oslo: Universitetsforlaget.

Hellevik, O. 1983. 'Politisk deltakelse I Norge - begrenset og skjev?' (Political Participation in Norway - Limited and Skewed?). Tidsskrift for samfunnsforskning 24: 3-30.

Hellevik, O. 1997. 'Class Inequality and Egalitarian Reform.' Acta Sociologica 40: 377-397.

Hellevik, O. 2000. 'A Less Biased Allocation Mechanism.' Acta Sociologica 43: 81-83.

Hellevik, O. 2002. 'Inequality versus Association in Educational Attainment Research: Comment on Kvininen, Ahola and Hedman.' Acta Sociologica 45: 151-158.

Hosmer, D. W. and S. Lemeshow. 1989. Applied Logistic Regression. New York: John Wiley \& Sons.

Iversen, G. 1979. Statistics for Sociology. Dubuque Iowa: C. Brown.

Kivinen, O., S. Ahola and J. Hedman. 2001. 'Expanding Education and Improving Odds. Participation in Higher Education in Finland in the 1980s and 1990s.' Acta Sociologica 44: $171-181$.

Kivinen, O., S. Ahola and J. Hedman. 2002. 'Changes to Differences in Expanding Higher Education: Reply to Hellevik.' Acta Sociologica 45: 159-162.

Lafferty, William M. 1981. Participation and Democracy in Norway. The Distant Democracy Revisted. Oslo: Universitetsforlaget.

Lambert, P. J. 1993. The Distribution and Redistribution of Income. A Mathematical Analysis. Manchester: Manchester University Press.

Lampard, R. 2000. 'Measuring Inequality in a Cross-tabulation with Ordered Categories: From the Gini Coefficient to the Tog Coefficient.' International Journal of Social Research Methodology 3: 1-14.

Leege, D. C. and W. L. Francis. 1974. Political Research. Design, Measurement and Analysis. New York: Basic Books.

Logan, J. A. 1996. 'Rules of Access and Shifts in Demand: A Comparison of Log-linear and Two-sided Logit Models.' Social Science Research 25: 174-199.

Mare, R. D. 1981. 'Change and Stability in Educational Stratification.' American Sociological Review 46: 72-87.

Marks, G.N. 2004. 'The Measurement of Socio-economic Inequalities in Education: A Further Comment.' Acta Sociologica 47: 91-93. 
Marshall, G. and A. Swift. 1999. 'On the Meaning and Measurement of Inequality.' Acta Sociologica 42: 241-250.

Marshall, G. and A. Swift. 2000. 'Reply to Ringen and Hellevik.' Acta Sociologica 43: $85-86$.

Martinussen, W. 1977. The Distant Democracy: Social Inequality, Political Resources and Political Influence in Norway. London: John Wiley and Sons.

Murphy, J. 1981. 'Class Inequality in Education: Two Justifications, One Evaluation But No Hard Evidence.' British Journal of Sociology 32: 82-101.

Murphy, J. 1990. 'A Most Respectable Prejudice: Inequality in Educational Research and Policy.' British Journal of Sociology 41: 29-54.

Ringen, S. 1997. Citizens, Families and Reform. Oxford: Clarendon Press.

Ringen, S. 2000. 'Inequality and Its Measurement.' Acta Sociologica 43: 84.

Ringen, S. 2005. Citizens, Families and Reform. 2nd ed. New Brunswick: Transaction Publishers.

Ringen, S. 2006. 'The Truth about Class Inequality.' Sociologický časopis/Czech Sociological Review 42: 475-491.

Saunders, P. 1996. Unequal but Fair? A Study of Class Barriers in Britain. London: IEA. 